\title{
THE UVEOSCLERAL OUTFLOW ROUTES
}

\author{
SIV F. E. NILSSON \\ Uppsala, Sweden
}

\begin{abstract}
SUMMARY
As there is no epithelial barrier between the anterior chamber and the ciliary muscle, aqueous humour may freely pass between the ciliary muscle bundles into the supraciliary and suprachoroidal spaces, from which it is drained through the sclera. This uveoscleral outflow of aqueous humour accounts for $40-60 \%$ of the total outflow in monkeys, whereas it is considerably less in $(3-8 \%)$ in cats and rabbits. Direct measurements in human eyes have suggested that less than $15 \%$ is drained by the uveoscleral routes. However, indirect calculations have given a value of about $35 \%$ in young adults and $3 \%$ in elderly persons ( $>60$ years). Under normal conditions, in monkeys, the uveoscleral outflow is insensitive to changes in the intraocular pressure, but cyclodialysis and experimental uveitis increase the uveoscleral outflow and make it more pressure sensitive. The uveoscleral outflow is decreased by contraction (pilocarpine) and increased by relaxation (atropine) of the ciliary muscle. Thus, changing the tone of the ciliary muscle may redistribute aqueous humour between the conventional and uveoscleral outflow routes. Prostaglandins decrease the intraocular pressure by increasing the uveoscleral outflow. Two mechanisms seem to contribute to this effect: relaxation of the ciliary muscle and changes in extracellular matrix, causing decreased resistance in the uveoscleral outflow routes.
\end{abstract}

The aqueous humour is formed by ciliary processes as a result of active transport of solutes (primarily sodium ions) over the double-layered ciliary epithelium and, secondary to this, diffusion of water. After entering the anterior chamber via the pupil, the aqueous humour is drained by two different pathways at the iridocorneal chamber angle. A part of the aqueous humour enters Schlemm's canal by way of the trabecular meshwork and then passes via the collector channels into the episcleral veins. This constitutes the conventional or trabecular outflow of aqueous humour. As there is no epithelial barrier

Correspondence to: Dr Siv F. E. Nilsson, Department of Physiology and Medical Biophysics, Box 572, S-751 23 Uppsala, Sweden. Fax: +46 18 174938. e-mail: siv.nilsson@fysiologi.uu.se. between the anterior chamber and the ciliary muscle, aqueous humour can pass between the muscle bundles into the supraciliary and suprachoroidal spaces, from which it is drained through the sclera. Outside the eye, fluid is returned to the systemic circulation via the lymphatic vessels in the orbit. These outflow routes are called the uveoscleral outflow routes. The existence and significance of this pathway for drainage of aqueous humour was first reported by Bill. ${ }^{1.2}$ In experiments designed to study the outflow of aqueous humour, he observed that the rate disappearance of radioactive albumin from the anterior chamber was higher than the increase in radioactivity in the blood, and simultaneously high radioactivity was observed in the ciliary body, choroid, sclera and episcleral tissues, indicating that a part of the albumin was delayed before it left in the eye. As there are no lymphatic vessels within the eye, this observation implied the existence of another outflow route for aqueous humour.

During the last decade, the uveoscleral outflow routes have attracted increased interest, as it was shown that prostaglandins decrease the intraocular pressure (IOP) by increasing the uveoscleral outflow. ${ }^{3-5}$ The purpose of the present paper is to give a brief review of the basic physiology and pharmacology of the uveoscleral outflow, with special emphasis on prostaglandins. More comprehensive reviews are given elsewhere. ${ }^{6,7}$

\section{METHODS FOR STUDYING THE UVEOSCLERAL OUTFLOW ROUTES AND QUANTITATIVE DETERMINATION OF THE UVEOSCLERAL OUTFLOW}

During its passage through the uveoscleral outflow routes the composition of the aqueous humour is changed due to exchange with the surrounding tissues. Low molecular weight substances can cross the capillary 'wall by diffusion, causing a net loss or gain depending on the concentration gradient, while large molecules (MW over 40 000) will move through the uveoscleral pathways by bulk flow. 
Even relatively large particles can pass into the uveoscleral outflow routes and have been used to study the morphology of the uveoscleral pathways. ${ }^{8-11}$ Latex spheres with a diameter up to $1 \mu \mathrm{m}$ enter the suprachoroid in monkeys ${ }^{8}$ and $\operatorname{dogs},{ }^{10}$ and in the equine eye even larger spheres $(3 \mu \mathrm{m})$ enter the anterior portion of the suprachoroid. ${ }^{11}$ In experiments with Thorotrast particles $(10 \mathrm{~nm})$ and latex spheres of different sizes $(0.1,0.5$ and $1.0 \mu \mathrm{m})$, Inomata and $\mathrm{Bill}^{9}$ observed that the Thorotrast particles, but not the latex spheres, entered the scleral substance of the cynomolgus monkey eye. In the loose connective tissue around nerves and blood vessels, Thorotrast particles as well as $0.1 \mu \mathrm{m}$ latex spheres were observed. These results indicate that the pathways through which fluid enters the suprachoroid are wider than those draining it and that fluid may leave the suprachoroid through the spaces along nerves and blood vessels as well as through the scleral substance. As the total pore area in the sclera is large, the restriction to flow through the sclera is small. Thus, the rate-limiting step in the uveoscleral pathways appears to lie between the anterior chamber and the suprachoroidal space.

From the anatomical arrangement, it is apparent that the uveoscleral outflow cannot be quantitatively sampled. Thus, more or less indirect techniques have to be used. The simplest and most reliable technique is the one originally described and used by Bill ${ }^{12}$ in monkeys. Briefly, the anterior chamber is perfused with radioactively labelled albumin (other high molecular weight tracer such as fluorescein isothiocyanate (FITC)-labelled dextran can also be used) during 1-2 hours. The anterior chamber is then rinsed by mock aqueous humour without the tracer. The animal is then killed and the amount of tracer present in the ocular and periocular tissues determined. The uveoscleral outflow can be calculated as the amount of tracer recovered in the tissues divided by the mean concentration of tracer in the anterior chamber during the experiment and the perfusion time. During recent years we have used another technique, in which the animal does not have to be killed. The aqueous humour flow was determined by an albumin dilution method, ${ }^{13}$ at the same time as the plasma radioactivity was determined. The aqueous humour that leaves the eye via the uveoscleral outflow is drained by the lymphatic vessels outside the eye and therefore the radioactive albumin leaving the eye via this route does not appear in plasma until several hours later. Thus, the plasma radioactivity can be used to calculate the conventional outflow and the uveoscleral outflow can be calculated as the difference between the aqueous humour flow and the conventional outflow.

For obvious reasons none of these methods can be used in humans, but it is possible to calculate the uveoscleral outflow indirectly. As the uveoscleral outflow is pressure independent (see below), the IOP is determined by the equation

or

$$
\mathrm{IOP}=\mathrm{P}_{\mathrm{v}}+\mathrm{F}_{\text {tra }} / \mathrm{C}
$$

$$
\mathrm{IOP}=\mathrm{P}_{\mathrm{v}}+\left(\mathrm{F}_{\text {in }}-\mathrm{F}_{\mathrm{us}}\right) / \mathrm{C}
$$

where $P_{v}$ is the episcleral venous pressure, $F_{\text {tra }}$ is the trabecular outflow, $F_{\text {in }}$ is the aqueous humour flow, $\mathrm{F}_{\mathrm{us}}$ is the uveoscleral outflow and $\mathrm{C}$ is the outflow facility. Thus, by measuring the IOP, the episcleral venous pressure, the aqueous humour flow and the outflow facility, the uveoscleral outflow can be calculated. However, the uncertainty in the measurement of each of these variables may cause considerable errors in the calculations.

\section{UVEOSCLERAL OUTFLOW IN DIFFERENT SPECIES}

Data from some studies on uveoscleral outflow in different species are given in Table I. In monkeys, the absolute values on uveoscleral outflow obtained in different studies vary, ${ }^{13,14}$ but the percentage of aqueous humour being drained via the uveoscleral route is normally in the range $40-60 \%$. In cats ${ }^{15}$ and rabbits ${ }^{16,17}$ the uveoscleral outflow seems to be of considerably less importance, constituting some $3-8 \%$ of the total drainage. In dogs ${ }^{18}$ approximately $15 \%$ is drained via the uveoscleral routes. Bill and Phillips ${ }^{19}$ used the tracer method to determine uveoscleral outflow in human eyes which were about to be enucleated due to intraocular tumours. In two eyes without pharmacological treatment, the uveoscleral outflow was $4 \%$ and $14 \%$ of total drainage, respectively. Assuming an episcleral venous pressure of $8 \mathrm{mmHg}$, Townsend and Bruba$\mathrm{ker}^{20}$ calculated the uveoscleral outflow to be $0.8 \mu \mathrm{l} /$ $\min (36 \%)$ in young adults. A preliminary report by

\begin{tabular}{|c|c|c|c|c|}
\hline Species & $\begin{array}{l}\text { USF }^{\mathrm{a}} \\
(\mu \mathrm{l} / \mathrm{min})(\%\end{array}$ & $\begin{array}{l}\text { USF }^{\mathrm{b}} \\
\% \text { of AHF) }\end{array}$ & Method $^{\mathrm{c}}$ & ${ }^{\mathrm{c}}$ Reference \\
\hline \multicolumn{5}{|l|}{ Monkey } \\
\hline Cynomolgus & 0.96 & 55 & A & 14 \\
\hline Vervet & 0.65 & 38 & A & 14 \\
\hline Cynomolgus & 0.61 & 51 & B & 13 \\
\hline Cat & 0.36 & 3 & A & 15 \\
\hline Rabbit (albino) & 0.11 & 3 & A & 16 \\
\hline Rabbit (albino) & 0.26 & $5-8$ & A & 17 \\
\hline \multicolumn{5}{|l|}{ Dog (beagle) } \\
\hline Normal & n.d. & 15 & A & 18 \\
\hline Glaucomatous & n.d. & 3 & A & 18 \\
\hline \multicolumn{5}{|l|}{ Human } \\
\hline Age $63 / 54$ years & n.d./0.28 & $4 / 14$ & A & 19 \\
\hline Age $24 \pm 0.5$ years & s 0.80 & 36 & $\mathrm{C}$ & 20 \\
\hline Age $20-30$ years & 1.04 & 38 & $\mathrm{C}$ & 21 \\
\hline Age $>60$ years & 0.09 & 3 & $\mathrm{C}$ & 21 \\
\hline
\end{tabular}

Table I. Uveoscleral outflow in different species 


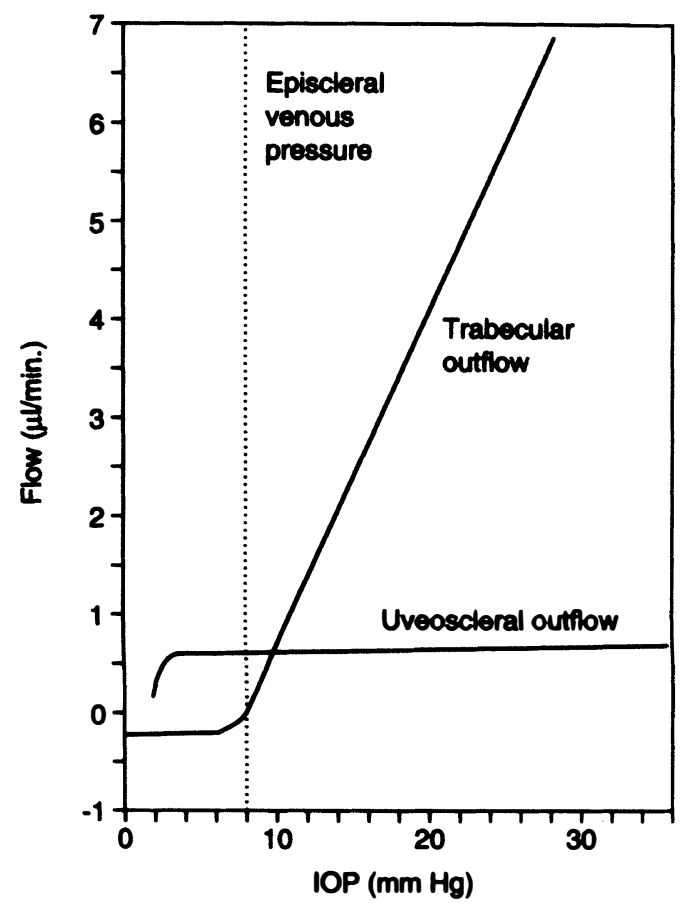

Fig. 1. Effect of increasing intraocular (IOP) on conventional and uveoscleral outflow of aqueous humour. (Reprinted from Nilsson and Bill ${ }^{23}$ ).

Toris et al. ${ }^{21}$ suggests that the uveoscleral outflow decreases with age, which may explain the difference in results between the two previous studies. Interestingly, the uveoscleral outflow appears to be lower in the glaucomatous than in the normal beagle. ${ }^{18}$

\section{EFFECTS OF INTRAOCLAR PRESSURE ON THE UVEOSCLERAL OUTFLOW}

Unlike the conventional outflow, uveoscleral outflow is minimally affected by increments in IOP in normal monkey eyes. ${ }^{12,22}$ Reducing the IOP to levels below $4 \mathrm{mmHg}$ causes an abrupt decrease in the uveoscleral outflow, however ${ }^{22}$ (Fig. 1). The driving force for the uveoscleral outflow is the difference in pressure between the anterior chamber and the suprachoroidal space. At normal IOP, the pressure in the suprachoroidal space is approximately $4 \mathrm{mmHg}$ lower than IOP, in monkeys, and when the IOP is artificially raised, the suprachoroidal pressure increases almost in parallel with IOP. ${ }^{24}$ Thus, the pressure head for uveoscleral outflow remains constant despite increasing IOP. Another reason for the pressure insensitivity could be that when the IOP is increased the ciliary muscle and the connective tissue in the supraciliary and suprachoroidal spaces become compressed, which causes increased resistance in the uveoscleral outflow routes.

Calculation of the outflow facility for the uveoscleral routes has given a value of $0.02 \mu \mathrm{l} / \mathrm{min} \mathrm{mmHg}$, to be compared with the outflow facility of $0.34 \mu \mathrm{l} /$ min $\mathrm{mmHg}$ for the conventional outflow under normal conditions. ${ }^{6}$ Cyclodialysis increases the uveoscleral outflow in rabbits $^{12}$ as well as in monkeys, ${ }^{25}$ and under such conditions the uveoscleral outflow seems to be more pressure dependent. ${ }^{26}$ Experimental uveitis causes a similar rise in uveoscleral outflow and pressure sensitivity. ${ }^{27}$

\section{PHARMACOLOGICAL MANIPULATION OF UVEOSCLERAL OUTFLOW}

Several different types of pharmacological agents have been reported to affect the uveoscleral outflow of aqueous humour. Some of these agents and their effects on uveoscleral outflow are listed in Table II.

\section{Muscarinic Effects}

It was shown early on that pilocarpine decreases uveoscleral outflow whereas atropine increases it. $^{28-30}$ These effects are caused by the structural changes associated with contraction and relaxation of the ciliary muscle. As the tendons of the ciliary muscle bundles are attached to the trabecular meshwork, contraction of the ciliary muscle separates the lamellae in the trabecular meshwork, which increases the outflow facility in the conventional routes. Simultaneously, the spaces between the ciliary muscle bundles become compressed, obstructing the uveoscleral outflow. Relaxation (atropine) of the ciliary muscle has the opposite effect, causing a widening of the spaces between the muscle bundle. Thus, alternating the tone of the ciliary muscle may redistribute the ouflow of aqueous humour between the conventional and uveoscleral outflow routes (Fig. 2).

\section{Adrenergic Agonists}

Adrenaline increases uveoscleral outflow in monkeys as well as in humans. ${ }^{20,31,32}$ This effect could be due to relaxation of the ciliary muscle mediated via adrenergic $\beta$-receptors. The $\beta$-selective agonist salbutamol increases uveoscleral outflow in humans. ${ }^{33}$

Table II. Effects of pharmological agents on the uveoscleral outflow

\begin{tabular}{lclc}
\hline Drug & Effect on USF $^{\text {a }}$ & Possible mechanism & Reference \\
\hline Pilocarpine & - & Contraction of CM & 28,29 \\
Atropine & + & Relaxation of CM & 29,30 \\
Adrenaline & + & Relaxation of CM? PGs? & $20,31,32$ \\
Salbutamol $\left(\beta_{2}\right)$ & + & Relaxation of CM? & 33 \\
$\boldsymbol{\alpha}_{2}$-agonists & \pm & $?$ & $35-37$ \\
Prostaglandins & + & Relaxation of CM,. changes in extracellular matrix & $3-5,46,47$ \\
\hline
\end{tabular}

USF, uveoscleral outflow; CM, ciliary muscle. 

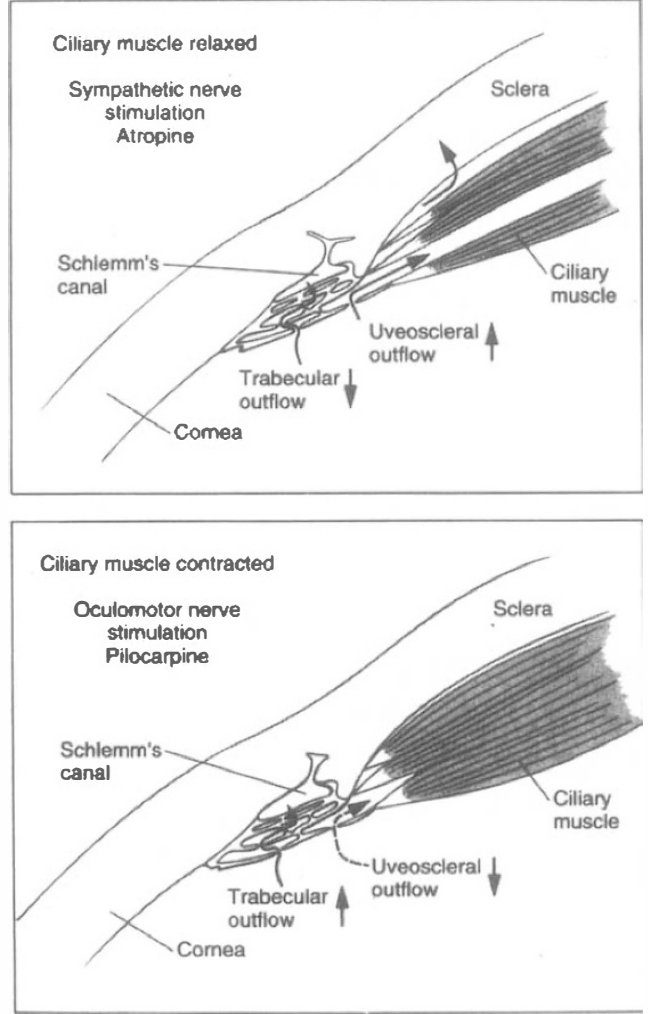

Fig. 2. Effect of ciliary muscle relaxation and contraction on conventional and uveoscleral outflow of aqueous humour. (Reprinted from Nilsson and Bill ${ }^{23}$ ).

It is also possible that the effect of adrenaline is secondary to release of prostaglandins (see below), as the adrenaline-induced reduction in IOP in humans is inhibited by indomethacin. ${ }^{34}$ Recently, a few reports have been published suggesting that $\alpha_{2}$-agonists could affect the uveoscleral outflow as well, but the effect seems to vary, depending on which agonist is used. ${ }^{35-37}$

\section{Prostaglandins}

Initially, prostaglandins (PGs) attracted interest mainly as possible mediators of ocular inflammation, as it was observed that topical or intracameral injection of PGs, in rabbits, caused hyperaemia, breakdown of the blood-aqueous barrier and an increase in IOP. Later studies revealed that the initial ocular hypertension was followed by an ocular hypotension of much longer duration. In other species (e.g. cats and monkeys) the initial hypertension was absent or much less marked, which suggested that PGs could be used in the medical treatment of glaucoma. This caused interest in the mechanism by which PGs decreased the IOP.

We showed that topical application of a single dose of $1 \mu \mathrm{g} \mathrm{PGF}_{2 \alpha^{-}}$isopropylester $\left(\mathrm{PGF}_{2 \alpha} \mathrm{IE}\right)$ increased the uveoscleral outflow in the cynomolgus monkey (Fig. 3). ${ }^{3,4}$ Similar results were obtained by Gabelt and Kaufman ${ }^{5}$ after multiple dosing. In our experiments, topical application of $10 \mu \mathrm{g}$ pilocarpine 70 minutes after the application of $\mathrm{PGF}_{2 \alpha}$-IE prevented the increase in uveoscleral outflow, and in monkeys with systemic pretreatment with atropine, topical application of $\mathrm{PGF}_{2 \alpha}$-IE had no effect on uveoscleral outflow. ${ }^{4}$ This suggests that after a single application of $\mathrm{PGF}_{2 \alpha} \mathrm{IE}$, the increase in uveoscleral outflow is mainly caused by relaxation of the ciliary muscle. This assumption is supported by the recent observation that $\mathrm{PGF}_{2 \alpha}$ relaxes the ciliary muscle from rhesus monkeys in vitro. ${ }^{38}$ However, daily treatment with $\mathrm{PGF}_{2 \alpha}$ during 4-5 days causes a larger drop in $\mathrm{IOP}^{39-41}$ than a single application, and the increase in uveoscleral outflow is more marked after multiple dosing (Nilsson and Mäepea, unpublished results). After multiple dosing with $\mathrm{PGF}_{2 \alpha}$, the spaces
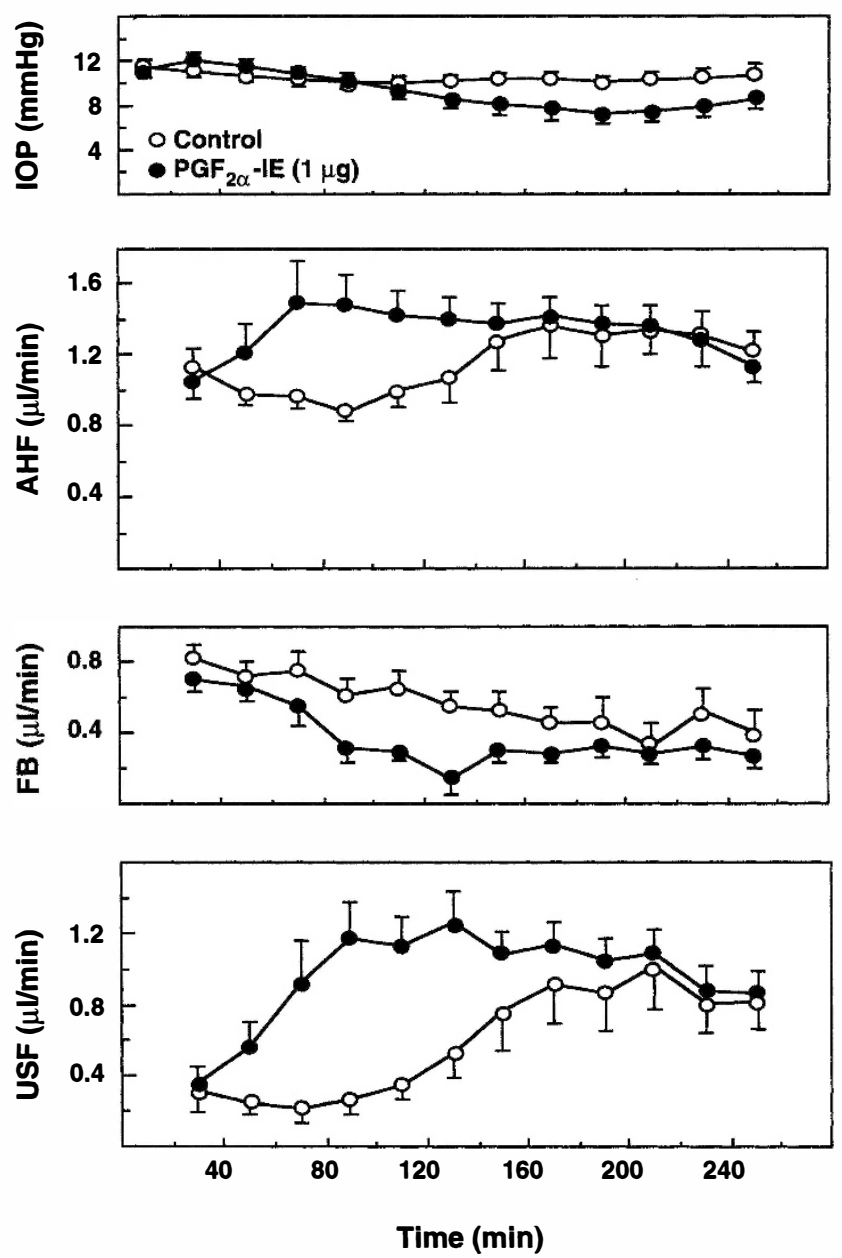

Fig. 3. Effect of unilateral topical application of prostaglandin $F_{2 \alpha}$-isopropylester $\left(P G F_{2 \alpha}-I E\right)$ on intraocular pressure (IOP), aqueous humour flow (AHF), flow of aqueous humour to blood $(F B)$ and uveoscleral outflow $(U S F)$, in cynomolgus monkeys. Each point represents the mean value during a 20 minute period. The application of $P G F_{2 \alpha}-I E(1 \mu g)$ to the experimental eye and vehicle $(10 \mu \mathrm{l})$ to the control eye was made in the middle of the first 20 minute period. Mean values and SEM are given $(\mathrm{n}=10)$. (Modified from Nilsson et al. ${ }^{4}$ ). 
between the ciliary muscle bundles are widened and there is a loss of collagen fibres of type I and III from the connective tissue in these spaces, ${ }^{42.43}$ suggesting that decreased resistance in the uveoscleral outflow routes may cause the enhanced uveoscleral outflow. Thus, the PG-induced increase in uveoscleral outflow may be caused by two different mechanisms: initial relaxation of the ciliary muscle and subsequently decreased resistance in the uveoscleral pathways due changes in the extracellular matrix.

The ability of pilocarpine to block the ocular hypotension caused by PGs seems to vary considerably depending on the experimental design and possibly also between species. In experiments with multiple dosing in monkeys, topical application of pilocarpine $(1 \mathrm{mg})$ prevents the decrease in IOP when it is given before the last dose of $\mathrm{PGF}_{2 \alpha}$, but not when it is given after the last dose of $\mathrm{PGF}_{2 \alpha}$. ${ }_{44.45}$ The ability of pilocarpine to block the PG-induced hypotension when it is given before $\mathrm{PGF}_{2 \alpha}$ could be due a pharmacokinetic effect: the contraction of the ciliary muscle preventing $\mathrm{PGF}_{2 \alpha}$ from reaching the ciliary muscle. As regards the inability of pilocarpine to reverse the hypotension when given after $\mathrm{PGF}_{2 \alpha}, 45$ the discrepancy compared with our results ${ }^{4}$ is most likely due to the differences in experimental design. In initial experiments (Nilsson et al., unpublished results) we used higher doses of pilocarpine (50-200 $\mu \mathrm{g})$ and applied it later, when the IOP was maximally reduced. In these experiments pilocarpine caused an intense miosis, which blocked the inflow of aqueous humour from the posterior to the anterior chamber almost completely. Occasionally, this block persisted for up to 2 hours. Determination of the plasma radioactivity indicated that outflow via the conventional route was about equal to the inflow via the pupil, suggesting that the uveoscleral outflow was completely stopped. Still the IOP did not return to baseline until after the block had been released. Furthermore, after a single dose $\mathrm{PGF}_{2 \alpha}$, as in our experiments, the increase in uveoscleral outflow is probably due mainly to relaxation of the ciliary muscle, while after multiple dosing decreased resistance in the uveoscleral pathway due to changes in the extracellular matrix may be of greater importance. Under the latter conditions, the uveoscleral outflow may become more pressure sensitive, ${ }^{5}$ and more difficult to block by ciliary muscle contraction. Concurrent administration of pilocarpine and the $\mathrm{PGF}_{2 \alpha}$ analogue PhXA41 (Latanoprost, Pharmacia Upjohn) which decreases IOP and increases uveoscleral outflow in humans as well as in monkeys, ${ }^{46,47}$ appears to have an additive effect on IOP in humans ${ }^{18}$ which indicates that combined treatment may be very useful in the treatment of glaucoma.

key words: Aqueous humour, Ciliary muscle, Intraocular messure, Prostaglandins, Uveoscleral outflow.

\section{REFERENCES}

1. Bill A. The aqueous humour drainage mechanism in the cynomolgus monkey (Macaca irus) with evidence for unconventional routes. Invest Ophthalmol Vis Sci 1965;4:911-9.

2. Bill A, Hellsing K. Production and drainage of aqueous humour in the cynomolgus monkey (Macaca irus). Invest Ophthalmol Vis Sci 1965;4:920-6.

3. Nilsson SFE, Sperber GO, Bill A. The effect of prostaglandin $\mathrm{F}_{2 \alpha}-1$-isopropylester $\left(\mathrm{PGF}_{2 \alpha}-\mathrm{IE}\right)$ on uveoscleral outflow. In: Bito LZ, Stjernschantz J, editors. The ocular effects of prostaglandins and other eicosanoids New York: Alan R Liss, 1989; 429-36.

4. Nilsson SFE, Samuelsson M, Bill A, Stjernschantz J. Increased uveoscleral outflow as a possible mechanism of ocular hypotension caused by prostaglandin $\mathrm{F}_{2 \alpha}-1$ isopropylester in the cynomolgus monkey. Exp Eye Res 1989;48:707-16.

5. Gabelt BT, Kaufman PL. Prostaglandin $\mathrm{F}_{2 \alpha}$ increases uveoscleral outflow in the cynomolgus monkey. Exp Eye Res 1989;49:389-402.

6. Bill A. Physiology of the outflow mechanism. In: Drance SM, editor. Applied pharmacology in the medical treatment of glaucomas. Orlando: Grune and Stratton, 1984;111-33.

7. Bill A. Uveoscleral drainage of aqueous humour: physiology and pharmacology. In: Bito LZ, Stjernschantz J, editors. The ocular effects of prostaglandins and other eicosanoids. New York: Alan R Liss, 1989;417-27.

8. Inomata H, Bill A, Smelser GK. Unconventional routes of aqueous humour outflow in the cynomolgus monkey (Macaca irus). Am J Ophthalmol 1972;73: 893-907.

9. Inomata $\mathrm{H}$, Bill A. Exit sites of uveoscleral flow of aqueous humour in cynomolgus monkey eyes. Exp Eye Res 1977;25:113-8.

10. Samuelson DA, Gum GG, Gelatt KN, Barrie KP. Aqueous outflow in the beagle: unconventional outflow, using different-sized microspheres. Am J Vet Res 1985;46:242-8.

11. Smith PJ, Samuelson DA, Brooks DE, Whitley RD. Unconventional aqueous humour outflow of microspheres perfused into the equine eye. Am J Vet Res 1986;47:2445-53.

12. Bill A. Conventional and uveo-scleral drainage of aqueous humour in the cynomolgus monkey (Macaca irus) at normal and high intraocular pressures. Exp Eye Res 1966;5:45-54.

13. Sperber GO, Bill A. A method for near-continuous determination of aqueous humour flow: effects of anaesthetics, temperature and indomethacin. Exp Eye Res 1984;39:435-53.

14. Bill A. Aqueous humour dynamics in monkeys (Macaca irus and Cercopithecus ethiops). Exp Eye Res 1971;11:195-206.

15. Bill A. Formation and drainage of aqueous humour in cats. Exp Eye Res 1966;5:185-90.

16. Bill A. The routes for bulk drainage of aqueous humour in rabbits with and without cyclodialysis. Doc Ophthalmol 1966;20:157-69.

17. Poyer JF, Gabelt B, Kaufman PL. The effect of topical PG $F_{2 \alpha}$ on uveoscleral outflow and outflow facility in the rabbit eye. Exp Eye Res 1992;54:277-83.

18. Barrie KP, Gum GG, Samuelson DA, Gelatt KN. Quantitation of uveoscleral outflow in normotensive and glaucomatous beagles by ${ }^{3} \mathrm{H}$-labelled dextran. Am J Vet Res 1985;46:84-8. 
19. Bill A, Phillips CI. Uveoscleral drainage of aqueous humour in human eyes. Exp Eye Res 1971;12:275-81.

20. Townsend DJ, Brubaker RF. Immediate effect of epinephrine on aqueous formation in the normal human eye as measured by fluorophotometry. Invest Ophthalmol Vis Sci 1980;19:256-66.

21. Toris CB, Yablonski ME, Camras CB, Gleason ML. Uveoscleral outflow decreases with age in ocular normotensive humans. Invest Ophthalmol Vis Sci (ARVO Suppl) 1996;37:410.

22. Bill A. Further studies on the influence of the intraocular pressure on aqueous humour dynamics in cynomolgus monkeys. Invest Ophthalmol Vis Sci 1967;6:364-72.

23. Nilsson SFE, Bill A. Physiology and neurophysiology of aqueous humour inflow and outflow. In: Podos SM, Yanoff M, editors. Textbook of ophthalmology (Kaufman PL, Mittag TW, editors), vol 7, Glaucoma. London: Mosby-Year Book, 1994;1.17-1.34.

24. Emi K, Pederson JE, Toris CB. Hydrostatic pressure of the suprachoroidal space. Invest Ophthalmol Vis Sci 1989;30:233-8.

25. Suguro K, Toris CB, Pederson JE. Uveoscleral outflow following cyclodialysis in the monkey eye using a fluorescent tracer. Invest Ophthalmol Vis Sci $1985 ; 26: 810-3$

26. Toris CB, Pederson JE. Effect of intraocular pressure on uveoscleral outflow following cyclodialysis in the monkey eye. Invest Ophthalmol Vis Sci 1985; 26:1745-9.

27. Toris CB, Pederson JE. Aqueous humour dynamics in experimental iridocyclitis. Invest Ophthalmol Vis Sci 1987;28:477-81.

28. Bill A, Wålinder PE. The effects of pilocarpine on the dynamics of aqueous humour in a primate (Macaca irus). Invest Ophthalmol Vis Sci 1966;5:170-5.

29. Bill A. Effects of atropine and pilocarpine on aqueous humour dynamics in cynomolgus monkeys (Macaca irus). Exp Eye Res 1967;6:120-5.

30. Bill A. Effects of atropine on aqueous humour dynamics in the vervet monkey (Cercopithecus ethiops). Exp Eye Res 1969;8:284-91.

31. Bill A. Early effects of epinephrine on aqueous humour dynamics in vervet monkeys (Cercopithecus ethiops). Exp Eye Res 1969;8:35-43.

32. Schenker HI, Yablonski ME, Podos SM, Linder L. Fluorophotometric study of epinephrine and timolol in human subjects. Arch Ophthalmol 1981;99:1212-6.

33. Coakes RL, Siah PB. Effects of adrenergic drugs on aqueous humour dynamics in the normal human eye. I. Salbutamol. Br J Ophthalmol 1984;68:393-7.

34. Camraș CB, Feldman SG, Podos SM, Christensen RE, Gardner SK, Fazio DT. Inhibition of the epinephrineinduced reduction of intraocular pressure by systemic indomethacin in humans. Am J Ophthalmol 1985; 100:169-75.
35. Wang RF, Lee PY, Taniguchi T, Becker B, Podos SM, Serle JB, Mittag TW. Effect of oxymetazoline on aqueous humour dynamics and ocular blood flow in monkeys and rabbits. Arch Ophthalmol 1993; 111:535-8.

36. Toris CB, Tafoya ME, Camras CB, Yablonski ME. Effects of apraclonidine in aqueous humour dynamics in human eyes. Ophthalmology 1995;102:456-61.

37. Toris CB, Gleason ML, Camras CB, Yablonski ME. Effects of brimonidine on aqueous humour dynamics in human eyes. Arch Ophthalmol 1995;113:1514-7.

38. Poyer JF, Millar C, Kaufman PL. Prostaglandin $F_{2 \alpha}$ effects on isolated Rhesus monkey ciliary muscle. Invest Ophthalmol Vis Sic 1995;36:2461-5.

39. Camras CB, Podos SM, Rosenthal JS, Lee PY, Severin $\mathrm{CH}$. Multiple dosing of prostaglandin $\mathrm{F}_{2 \alpha}$ or epinephrine on cynomolgus monkey eyes. I. Aqueous humour dynamics. Invest Ophthalmol Vis Sci 1987;28: 463-9.

40. Crawford K, Kaufman PL, Gabelt BT. Effects of topical $\mathrm{PGF}_{2 \alpha}$ on aqueous humour dynamics in cynomolgus monkeys. Curr Eye Res 1987;6:1035-44.

41. Crawford KS, Kaufman PL. Dose-related effects of prostaglandin $F_{2 \alpha}$ isopropylester on intraocular pressure, refraction, and pupil diameter on monkeys. Invest Ophthalmol Vis Sci 1991;32:510-9.

42. Lütjen-Drecoll E, Tamm E. Morphological study of the anterior segment of cynomolgus monkey eyes following treatment with prostaglandin $F_{2 \alpha}$. Exp Eye Res 1988;47:761-9.

43. Tamm E, Rittig M, Lütjen-Drecoll E. Electron microscopy and immunohistochemical studies of the intraocular pressure lowering effect of prostaglandin $F_{2 \alpha}$. Fortschr Ophthalmol 1990;87:623-9.

44. Crawford K, Kaufman PL. Pilocarpine antagonizes prostaglandin $\mathrm{F}_{2 \alpha}$-induced ocular hypotension in monkeys. Arch Ophthalmol 1987;105:1112-6.

45. Millar JC, Kaufman PL. $\mathrm{PGF}_{2 \alpha} /$ pilocarpine interactions on IOP and accommodation in keys. Exp Eye Res 1995;61:677-83.

46. Toris CB, Camras CB, Yablonski ME. Effects of PhXA41, a new prostaglandin $F_{2 \alpha}$ analog, on aqueous humour dynamics in human eyes. Ophthalmology 1993;100:1297-304.

47. Stjernschantz J, Selén G, Sjöquist B, Resul B. Preclinical pharmacology of latanoprost, a phenylsubstituted $\mathrm{PGF}_{2 \alpha}$ analogue. In: Samuelsson $\mathrm{B}$ et al., editors. Advances in prostaglandin, thromboxane, leukotriene research, vol 23. New York: Raven Press, 1995:513-8.

48. Friström B, Nilsson SE. Interaction of PhXA41, a new prostaglandin analogue, with pilocarpine: a study on patients with elevated intraocular pressure. Arch Ophthalmol 1993;111:662- 5. 